\title{
Evaluation of the safety and satisfaction of rheumatic patients with accelerated infliximab infusion
}

Jozélio Freire de Carvalho ${ }^{1,2^{*}}$, Maria Natividade Pereira dos Santos ${ }^{1}$, Joyce Meyre Vieira de Oliveira', Andrea Nogueira S. Lanty Silva', Roberto Paulo Correia de Araujo ${ }^{1,2}$ and Juliana Bahia Cardozo ${ }^{1}$

\begin{abstract}
Introduction: Infliximab infusion generally occurs in $2-4 \mathrm{~h}$. Recent studies have suggested the possibility of accelerated infusion ( $1 \mathrm{~h}$ ) of this drug.

Objective: To evaluate the safety of accelerated infliximab infusion in patients with rheumatic diseases. In addition, patient satisfaction was also assessed.

Methods: A prospective, single-center, non-randomized study with 34 patients with rheumatic diseases was conducted from July to November 2016. Patients with the following were excluded: history of allergic reaction to biologics, asthma or severe atopy. All patients previously received a 2- to 3-h infliximab infusion. The infusion rate was accelerated to $1 \mathrm{~h}$, and premedication was excluded. The infusion was monitored in all patients.
\end{abstract}

Results: A total of 34 patients were included in the study [rheumatoid arthritis $(n=16)$, ankylosing spondylitis $(n=$ 15), psoriatic arthritis $(n=2)$ and enteropathic arthropathy $(n=1)$ ], with an average age of $48.7 \pm 18.6$ years; $55.5 \%$ of the patients were female, and $29.4 \%$ were white. The duration of disease was $9.5 \pm 9.2$ years, and the duration of infliximab use was $38.9 \pm 27.6$ months, with a mean dose per infusion of $414.2 \pm 158.1$ (range, 200-800) mg. The mean infliximab infusion time prior to the study was $2.2 \pm 0.4 \mathrm{~h}$. A total of $6(17.6 \%)$ patients received premedication. The premedication was suspended. There were no adverse effects during or after infusion. Ninetyseven percent of the patients and 100\% of the health workers were satisfied with the accelerated infusion.

Conclusion: Our data support the safe use of accelerated infliximab infusion in rheumatic patients, with high satisfaction among patients and health workers.

Keywords: Infliximab, Infusion, Immunobiologics, Rheumatoid arthritis, Ankylosing spondylitis, Psoriatic arthritis, Spondyloarthritis

\section{Background}

Immunobiological drugs have become increasingly used in the treatment of rheumatic diseases. An example is the use of inhibitors of tumor necrosis factor (anti-TNF) in the treatment of rheumatoid arthritis and spondyloarthritis [1]. However, the infusion of anti-TNF may lead to infusion-related complications, requiring its supervision and monitoring.

\footnotetext{
*Correspondence: jotafc@gmail.com

'SOS Vida, Rheumatology Unit, Salvador, Bahia, Brazil

${ }^{2}$ Institute of Health Sciences, Universidade Federal da Bahia (Federal

University of Bahia), Salvador, Bahia, Brazil
}

Infliximab, a chimeric anti-TNF monoclonal antibody, is an intravenous medication for which infusion of at least $2 \mathrm{~h}$ and a 1-h clinical observation period are recommended due to the risk of infusion-related complications [2]. In the modern world, where processes need to be faster both to reduce costs and to minimize the time spent by the patient using the hospital structure, there is a need to attempt to accelerate the infliximab infusion process. Many experiments, including meta-analyses, mainly regarding the treatment of inflammatory bowel diseases, have been performed that have demonstrated the safety of an accelerated infusion of this biologic [3].

(c) The Author(s). 2018 Open Access This article is distributed under the terms of the Creative Commons Attribution 4.0 International License (http://creativecommons.org/licenses/by/4.0/), which permits unrestricted use, distribution, and 
Regarding the treatment of rheumatic diseases, articles have already been published that have evaluated the safety of accelerated infliximab infusion rates of $30 \mathrm{~min}$ to $1 \mathrm{~h}$ [4-8]. However, we did not find any Brazilian studies that employed this infusion technique.

The aim of the present study was to evaluate the safety of accelerated infliximab infusion in patients with rheumatic diseases. Secondarily, the authors evaluated whether patients and health workers involved in this treatment were satisfied.

\section{Methods}

This prospective, single-center, non-randomized, open-label study included adult patients ( $>18$ years of age) with a confirmed diagnosis of rheumatic diseases using infliximab. The patients were included in the study if they presented with rheumatoid arthritis (RA) (American College of Rheumatology- ACR criteria) [9], ankylosing spondylitis (AS) [10], psoriatic arthritis (PsA) [11] and Crohn's disease [12] and were regularly monitored in our infusion clinic. Exclusion criteria were history of infusion reaction prior to immunobiological therapy, refusal to participate in the study and history of asthma or severe atopy. Clinical and laboratory data were obtained after consulting the medical records and performing the clinical examination. Ethical local committee approved this study.

\section{Infusion protocol}

Patients with RA received a dose of 3 or $5 \mathrm{mg} / \mathrm{kg}$ (if refractory to the previous dose), and patients with AS, PsA and Crohn's disease received $5 \mathrm{mg} / \mathrm{kg}$, all receiving a stable dose, every 8 weeks. The accelerated infusion consisted of starting at half the rate in the first $15 \mathrm{~min}$ to check for infusion reaction; the remainder of the volume was infused in the remaining $45 \mathrm{~min}$. Subsequently, the patients underwent post-infusion monitoring lasting 30 min. A nurse trained in infliximab infusion recorded all infusion data and monitored vital data during and after the infusion. In case of any adverse effects, the infusion was stopped immediately. Depending on the severity of the infusion reaction, the emergency response protocol consisted of decreasing the infusion rate, stopping the infusion and intravenously injecting diphenhydramine $(50 \mathrm{mg})$, followed by methylprednisolone (125 mg) and, if necessary, adrenaline [13].

\section{Satisfaction of patients and health workers}

At the end of the last infusion, patient satisfaction was measured by answering the following question: "Did the change in infusion time improve your quality of life?" Responses ranged from 1 to 10 on a Likert scale. For health workers (nursing and nursing technicians) who dealt directly with the infusion, the following question was asked: "Did the change in infusion time improve the quality of care?" Responses ranged from 1 to 10 on a Likert scale.

\section{Statistical analysis}

Descriptive statistics were used. Values are expressed as the means and standard deviations or medians or percentages. The data were entered into Microsoft Excel software for analysis.

\section{Results}

A total of 34 patients were included, with a mean age of $48.7 \pm 18.6$ years (19-79 years); $55.5 \%$ of the patients were female, and $29.4 \%$ were white. The patients had the following conditions: rheumatoid arthritis $(n=16)$, ankylosing spondylitis $(n=15)$, psoriatic arthritis $(n=2)$ and Crohn's disease $(n=1)$. The mean disease duration was $9.5 \pm 9.2$ years.

The mean duration of infliximab use was $38.9 \pm$ 27.6 months. The mean dose per infliximab infusion was $414.2 \pm 158.1 \mathrm{mg}$, ranging from 200 to $800 \mathrm{mg}$. Regarding other medications, $10(29.4 \%)$ patients received methotrexate (5 RA, 4 AS and 1 PsA), 3 (8.8\%) patients received leflunomide, and only 2 patients were taking prednisone $5 \mathrm{mg} /$ day. Positive results for rheumatoid factor and anti-cyclic citrullinated peptide antibody (anti-CCP) were observed in 69 and $63 \%$ of the patients with RA, respectively. A total of $6(17.6 \%)$ patients used premedication with corticoid and antihistamine.

The mean infusion time prior to the infliximab study was $2.2 \pm 0.4 \mathrm{~h}$, ranging from 2 to $3 \mathrm{~h}$. A total of 6 (17.6\%) patients received premedication: 3 patients with RA and 3 patients with AS.

After the accelerated infusion protocol was started, all patients stopped receiving premedication. There were no adverse effects during or after infusion in any of the patients included in this study. A mean of $2.7 \pm 0.7$ infusions per patient was performed during the study.

Regarding satisfaction, $97 \%$ answered the question: "Did the change in infusion time improve your quality of life?" with scores between 8 and 10. All (100\%) health workers gave a score of 10 to the following question: "Did the change in infusion time improve the quality of care?"

It is assumed that there was a reduction of approximately $1 \mathrm{~h} 30 \mathrm{~min}$ in each patient's time in the hospital. This inference was based on the 1 -h reduction in infusion time plus the 30 min saved by eliminating the need for premedication preparation and application.

\section{Discussion}

The present study demonstrates the safety of accelerated infliximab infusion in adult patients with rheumatic diseases, all without previous history of infusion reactions. 
The relevance of the present study is supported by the rigorous patient selection criteria, with all the participants meeting the classification/diagnostic criteria for their diseases, along with the exclusion of people with prior allergic reactions or severe atopy. These criteria may justify the absence of adverse effects during the present study. In fact, if these conditions were not excluded, the risk of anaphylaxis could be increased.

A meta-analysis that included 10 studies comparing 1-h (8497 infusions) and 2-h (13,147 infusions) infliximab infusions showed a reduction in the rate of infusion reactions when the drug was administered for $1 \mathrm{~h}$ [1]. The present study did not result in any adverse infusion reactions during the study period.

Reactions to infliximab infusion occur in approximately $2-3 \%$ of infusions [14]. Interestingly, our study showed no adverse effects. In addition, accelerated infusion may increase adherence to treatment. Indeed, in patients with enteropathic arthropathy, poor adherence has been reported, ranging from 25 to 35\%, which increases medical costs and hospitalization risk [15].

There are some limitations in the present study, the first being the relatively small number of patients included. To address this issue, new studies with large numbers of participants should be conducted. Another factor was the exclusion of patients with a previous history of severe atopy or infusion reaction, which may have contributed to the absence of adverse events. New studies that include individuals with a history of atopy could also be performed, obviously with careful monitoring and adequate preparation for an emergency intervention. The infliximab dose used here $(3-5 \mathrm{mg} / \mathrm{kg}$ ) may also preclude the capacity to extend its conclusions to larger doses, which are often used in refractory cases.

It should be noted that all patients included in this study were already undergoing treatment with infliximab. For new patients, the literature recommends that the first infusion or the induction phase be performed within the usual 2-h period.

In summary, the present study demonstrates the excellent tolerability of the accelerated infliximab infusion in adult patients with rheumatic diseases, without previous history of infusion reaction. In addition, the results of this study precluded the need for premedication. In addition, great satisfaction was expressed among both patients and health workers.

Availability of data and materials

All data and materials of this manuscript are available for consultation.

\section{Authors' contributions}

JF de C Idea about the manuscript, writting, data analysis, review; MNP dos S data collection, data analysis; JMV de O data collection, data analysisi, AN S. LS data collection, data analysis; RPC de A writting, data analysis, review; JBC writting, data analysis, review.
Competing interests

The authors declare no competing interests.

\section{Publisher's Note}

Springer Nature remains neutral with regard to jurisdictional claims in published maps and institutional affiliations.

Received: 26 March 2018 Accepted: 15 June 2018

Published online: 03 August 2018

References

1. Titton DC, Silveira IG, Louzada-Junior P, Hayata AL, Carvalho HM, et al. Brazilian biologic registry: BiobadaBrasil implementation process and preliminary results. Rev Bras Reumatol. 2011;51:152-60.

2. de Moraes JC, Aikawa NE, Ribeiro AC, Saad CG, Carvalho JF, Pereira RM, Silva CA, Bonfá E. Immediate complications of 3,555 injections of anti-TNFa. Rev Bras Reumatol. 2010;50:165-75.

3. Neef HC, Riebschleger MP, Adler J. Meta-analysis: rapid IFX infusions are safe. Alimentary Pharmacology and Therapeuticc. 2013;38:365-76.

4. Bañuelos-Ramírez D, Ramirez-Palma MM, Balcazar-Sanchez ME, SanchezAlonso S. Rapid application of infliximab. Efficacy complications. Reumatol Clin. 2007:3:171-5

5. Buch MH, Bryer D, Lindsay S, Rees-Evans B, Fairclough A, Emery P. Shortening infusion times for infliximab administration. Rheumatology (Oxford). 2006;45:485-6.

6. El Miedany Y, Palmer D. Infliximab infusion therapy in inflammatory arthritis: assessment of the accelerated infusion protocol in comparison to the standard infusion approach. Rheumatology (Oxford). 2011;50:97-97.

7. hergy WJ, Isern RA, Cooley DA, et al. Open label study to assess infliximab safety and timing of onset of clinical benefit among patients with rheumatoid arthritis. J Rheumatol. 2002;29:667-77.

8. Lee TW, Singh R, Fedorak RN. A one-hour infusion of infliximab during maintenance therapy is safe and well tolerated: a prospective cohort study. Aliment Pharmacol Ther. 2011;34:181.

9. Arnett FC, Edworthy SM, Bloch DA, Mcshane DJ, Fries JF, Coope NS, et al. The American rheumatism association 1987 revised criteria for the classification of rheumatoid arthritis. Arthritis Rheum. 1988;31:315-24.

10. Bennett PH, Wood PHN. Population studies of the rheumatic diseases. New York: Excerpta Medica; 1968. p. 456.

11. Moll JM, Wright V. Psoriatic arthritis. Semin Arthritis Rheum. 1973;3:55-78.

12. Dougados $M$, vander Linden $S$, Juhlin $R$, Huitfeldt $B$, Amor B, Calin A, et al. The European Spondylarthropathy study group preliminary criteria for the classification of spondylarthropathy. Arthritis Rheum. 1991;34:1218-27.

13. Protocolo de actuação em caso de reacção à infusão de infliximab. Grupo de Estudos de Artrite Reumatoide da Sociedade Portuguesa de Reumatologia. Acta Reum Port. 2005;30:355-9.

14. Van Assche G, Lewis JD, Lichtenstein GR, et al. The London position statement of the world congress of gastroenterology on biological therapy for IBD with the European Crohn's and colitis organisation: safety. Am J Gastroenterol. 2011;106:1594-602.

15. Kane SV, Chao J, Mulani PM. Adherence to infliximab maintenance therapy and health care utilization and costs by Crohn's disease patients. Adv Ther. 2009;26:936-46.

Ready to submit your research? Choose BMC and benefit from:

- fast, convenient online submission

- thorough peer review by experienced researchers in your field

- rapid publication on acceptance

- support for research data, including large and complex data types

- gold Open Access which fosters wider collaboration and increased citations

- maximum visibility for your research: over $100 \mathrm{M}$ website views per year

At BMC, research is always in progress.

Learn more biomedcentral.com/submissions 